\title{
KULTURA ZDRAVSTVENIH INFORMACIJA U HRVATSKOJ
}

\author{
Ivan Pristaš, Damir Ivanković, Maja Valentić, Srđan Golubović, \\ Borna Pleše, Marko Brkić, Boris Barto i Tamara Poljičanin
}

\author{
Hrvatski zavod za javno zdravstvo \\ Rockefellerova 7, 10000 Zagreb \\ e-mail: ivan.pristas@hzjz.hr
}

Sažetak

Rad stavlja naglasak na informacijsku kulturu kao dio organizacijske kulture koja odrectuje upravljanje informacijama te načine njezina korištenja u sustavu. Zdravstvene informacije predstavljaju iznimno važan resurs $u$ planiranju, vođenju $i$ procjeni zdravstvenog sustava, dok upravljanje informacijama u zdravstvu ima izravan učinak na funkcioniranje zdravstvenog sustava kao i na kvalitetu zdravstvene zaśtite. U radu se navodi nekoliko primjera nedostatne informacijske kulture i manjkavog upravljanja informacijama u projektima implementacije informacijsko-komunikacijskih tehnologija u zdravstvu Republike Hrvatske. Uzrok je prepoznat u izostanku sustavnog i strateškog upravljanja eZdravljem, a navedeni primjeri ukazuju na probleme netransparentnosti sustava i njegovog preskupog održavanja, na institucionalnu fragmentarnost, nedostatak sustavno planiranih ljudskih $i$ financijskih resursa, izostanak definiranih uloga i ovlasti te komunikacije medu dionicima, kao i na nepostojanje standarda, procedura i evaluacija. Autori predlažu ozbiljan pristup strateškim odrednicama upravljanja zdravstvenim podacima $i$ informacijama kao kritičan korak ka sustavnom i uspjeśnom upravljanju eZdravljem. Kao moguće aktivnosti predlaže se jačanje institucijskih kapaciteta, uspješnija komunikacija te podjela ovlasti i uloga dionika koji bi informacijama trebali upravljati.

Ključne riječi: informacijska kultura, eZdravlje, upravljanje podacima, zdravstveni sustav

\section{UVOD}

Koncept organizacijske kulture već je desetljećima dio organizacijskog i menadžerskog korpusa, a istraživanja organizacijske kulture sporadično se provode i na razini zdravstvenih organizacija. Bez obzira na još uvijek slabu istraženost i nedovoljnu dokazanost veze između organizacijske kulture i radnog učinka (Davies i sur., 2000; Scott i sur., 2003a), u zdravstvenim se krugovima promjena organizacijske kulture često navodi kao jedan od važnijih preduvjeta za poboljšanje funkcioniranja zdravstvenog sustava i posljedično zdravstvene zaštite, bivajući pritom dijelom zdravstvenih reformi. U raspravama o kvaliteti zdravstvene zaštite sve se više ističe potreba da strukturnu i proceduralnu promjenu organizacije prati i kulturna promjena - promjena u vrijednostima, stavovima, normama, praksama i ritualima.

$S$ obzirom na to da su podaci i informacije iznimno važan upravljački resurs u planiranju, vođenju i procjeni zdravstvenog sustava, u radu se stavlja fokus na informacijsku 
kulturu, tj. na dio organizacijske kulture koji određuje upravljanje informacijama te načine njezina korištenja u sustavu. Primjena informacijsko-komunikacijskih tehnologija, koja se zbog nekompetitivne prirode zdravstva i kompleksnosti organizacije i procesa razvijala nešto sporije nego u drugim sektorima, značajno mijenja načine, oblike i mjesta prikupljanja, analize i korištenja podataka. Time se može značajno utjecati na funkcioniranje zdravstvenog sustava kao i na kvalitetu zdravstvene zaštite. Pri implementaciji informacijsko-komunikacijskih tehnologija cilj ili poželjan učinak obično je povećanje kvalitete zdravstvene zaštite, no mogući su i česti, obrnuti scenariji. Stoga je posebno nužno sustavno i strateški pristupiti upravljanju zdravstvenim podacima te evaluaciji njezinih učinaka. Kao polaznu točka za razumijevanje kulture informacija, važno je razlikovati upravljanje zdravstvenim informacijama, kao glavnu djelatnost zdravstvenih stručnjaka, od upravljanja zdravstvenim informatičkim sustavima.

Nakon teorijskog određenja organizacijske i informacijske kulture, u radu se navodi nekoliko primjera nedostatne informacijske kulture i manjkavog upravljanja informacijama u projektima implementacije informacijsko-komunikacijske tehnologije (IKT) u zdravstvu, uzrokovane izostankom sustavnog i strateškog upravljanja u eZdravlju. Navedeni primjeri ukazuju na probleme netransparentnosti sustava i njegovog preskupog održavanja, na institucionalnu fragmentarnost, nedostatak sustavno planiranih ljudskih i financijskih resursa, izostanak definiranih uloga i ovlasti te komunikacije među dionicima, na nepostojanje standarda, procedura i evaluacija.

\section{ORGANIZACIJSKA KULTURA}

Iako ne postoji općeprihvaćena definicija organizacijske kulture, u literaturi se najčešće javljaju dva pristupa definiranju tog koncepta. Prema prvom pristupu, kojem se priklanja i ovaj rad, kultura predstavlja ono što organizacija jest, obuhvaćajući cjelokupan karakter i iskustvo organizacijskog života, služeći kao metafora za opisivanje same organizacije. $S$ druge strane, kultura je atribut organizacije, nešto što organizacija ima, što je odlikuje zajedno s atributima kao što su, primjerice, struktura i strategija (Davies i sur., 2000; Scott i sur., 2003a).

Organizacijska kultura uključuje zajednička uvjerenja članova organizacije, stavove, vrijednosti i norme ponašanja, prakse i rituale; ona odražava zajednički način pridavanja smisla organizaciji.

S obzirom na navedene elemente, organizacijska kultura može biti integrirana (konsenzus na razini stajališta i ponašanja unutar organizacije), diferencirana (razne grupe unutar organizacije posjeduju raznolika, često neuskladiva uvjerenja i norme) i fragmentirana (potpuno razilaženje i fragmentiranje unutar organizacije) (Davies i sur., 2000). Neke od dimenzija organizacijske kulture koje mogu utjecati na njezinu koheziju su: stav prema inovacijama i poduzimanju rizika, fleksibilnost ili stabilnost, obrasci komunikacije, orijentiranje na ishod ili na proces, fokus na unutrašnje ili na izvanjske elemente organizacije, poticanje ili protivljenje raznolikosti unutar organizacije, stavovi prema organizacijskim ljudskim resursima i njihovo vrednovanje, podržavanje i nagrađivanje 
individualizma ili timskog rada, ponašanje prema organizacijama sličnog usmjerenja itd. (Davies i sur., 2000).

S obzirom na fleksibilnost ili stabilnost te unutarnji (integracijski) ili vanjski fokus (diferencijacijski) organizacije, Cameron i Quinn (2011, prema Choo, 2013) razvili su četiri tipa organizacijske kulture. Adhokratska kultura (engl. adhocracy culture) bazira se na fleksibilnosti i raznolikosti te usmjerenosti na izvanjske elemente organizacije. U njoj se nagrađuje i potiče kreativnost, eksperimentiranje, preuzimanje rizika i inovativnost. $\mathrm{Na}$ tjecateljska kultura (engl. market culture) temelji se na stabilnosti i vanjskom fokusu, uz karakteristike kao što su kompetitivnost, tržišna orijentacija, orijentiranost na rezultate, dug i predan rad na ostvarivanju ciljeva. Klanska kultura (engl. clan culture) temelji se na fleksibilnosti i unutarnjem fokusu, a usmjerena je na vrijednosti kao što su suradnja, kohezija, timski rad, lojalnost, obiteljska atmosfera i osjećaj pripadnosti. Hijerarhijsku organizacijsku kulturu (stabilnost i unutarnji fokus) određuju kategorije kao što su stabilnost, poredak, uniformnost, poštivanje propisa i formalizacija procedura.

Potreba za promjenom organizacijske kulture često se spominje kao opći preduvjet za poboljšanjem funkcioniranja organizacija. Pritom se najčešće poduzima u slučaju uočene stagnacije ili krize unutar organizacije, može se provoditi i planski, a često je i marginalno sastavni dio projekata unaprjeđenja poslovnih procesa. Promjena na svim razinama organizacijske kulture neizvediva je i nepoželjna.

Svaka strategija promjene organizacijske kulture mora biti selektivna, uz pažljiv odabir aspekata koje treba zadržati i one koje je potrebno izmijeniti (Davies i sur., 2000; Scott i sur., 2003a). Uspješne kulturne promjene uzimaju u obzir potrebe, strahove i motivacije osoblja na svim razinama hijerarhije.

Pomoć pri odabiru strategije i njenom razvoju mogu pružiti instrumenti za procjenu organizacijske kulture. $S$ obzirom na razlike u dimenzijama organizacijske kulture koje evaluiraju, na razlike u jednostavnosti korištenja i znanstveno-teorijskoj utemeljenosti, pri odabiru instrumenta treba voditi računa o definiciji organizacijske kulture od koje se polazi, o cilju ispitivanja, o namjerama korištenja rezultata i dostupnosti resursa za istraživanje (Scott i sur., 2003b).

Planiranje i provedba promjene organizacijske kulture zahtjevan je, nesiguran i riskantan pothvat koji se lako može opstruirati bilo zbog nedostatka odgovarajućeg vodstva, kompleksnosti same organizacije, prevelikih razilaženja među organizacijskim supkulturama, utjecaja izvana ili neke druge barijere (Scott i sur., 2003a). Potrebno je imati na umu da svaki pokušaj utjecanja na određene dimenzije organizacijske kulture treba biti dio šireg skupa planiranih aktivnosti za poboljšanje. Organizacijska kultura ne može se rješavati izolirano od pitanja kao što su, primjerice, organizacijska struktura ili financijske mogućnosti (Davies i sur., 2000).

\section{INFORMACIJSKA KULTURA}

Iako u literaturi ne postoji konsenzus oko definicije informacijske kulture, kao opće referentno mjesto nametnula se definicija Curryja i Moorea koja kaže da je informacijska kultura „kultura u kojoj je prepoznata vrijednost i korisnost informacija u postizanju 
operativnih i strateških ciljeva, u kojoj informacije čine osnovu donošenja odluka na razini organizacije, a učinkovit informacijski sustav omogućen je korištenjem informacijske tehnologije" (2003:94). S obzirom na to da se informacijska kultura smatra elementom organizacijske kulture, definirana je također kao skup organizacijskih normi, vrijednosti i praksi koje utječu na stvaranje i korištenje informacija. Informacijska kultura odražava uporabu informacija (engl. information use) u organizaciji, tj. način na koji članovi organizacije vide svoj rad s informacijama, odnosno njihovo kreiranje, dijeljenje, obradu i održavanje (Choo i sur., 2008).

Prema Marchandu i sur. (2001), informacijsku kulturu organizacije mogu odredivati sljedeća ponašanja i vrijednosti: informacijski integritet (uporaba informacija na povjerljiv i principijelan način na individualnoj i organizacijskoj razini), formalnost (spremnost za korištenje institucionaliziranih podataka uz davanje prednosti njima naspram neslužbenih izvora), kontrola (mogućnost članova organizacije za upravljanje i nadziranje svog učinka), dijeljenje (spremnost na pružanje informacija na odgovarajući i suradnički način), transparentnost (otvorenost prema prezentiranju grešaka i neuspjeha, dopuštanje učenja iz pogrešaka) i proaktivnost (aktivna briga o osiguravanju i primjeni novih informacija kao odgovor na poslovne promjene i inovacije). Među spomenutim ponašanjima i vrijednostima, za informacijsku kulturu zdravstvene organizacije najtipičniji su transparentnost, proaktivnost i dijeljenje (Choo i sur., 2008). Da bi interakcija ljudi, informacija i tehnologije u bilo kojoj organizaciji, pa tako i u zdravstvenoj, polučila uspješan radni učinak, potrebno je promovirati i njegovati ponašanja i vrijednosti koja potiču produktivnu uporabu informacija, ali isto tako i razviti sposobnost učinkovitog upravljanja aplikacijama informacijske tehnologije te infrastrukturom, kao i sposobnost učinkovitog upravljanja informacijama, odnosno njihova prikupljanja, organiziranja, obrade i održavanja (Marchand i sur., 2001). Bergeron i sur. (2007) ističu kako na ishode uporabe informacija utječe upravljanje informacijama (razvoj politika, strategija i sustava) i informacijska kultura (informacijske vrijednosti, norme i ponašanja). Njihovo razumijevanje omogućuje organizacijama da identificiraju potencijalne prednosti i slabosti svojeg korištenja informacija, da procijene svoju sposobnost u postizanju željenih ciljeva i ishoda korištenja informacija te da sukladno odnosu poželjnih i stvarno zastupljenih dimenzija informacijske kulture poduzmu odgovarajuće korake za promjenom.

\section{KULTURA ZDRAVSTVENIH INFORMACIJA U HRVATSKOJ}

Prema definiciji prisutnoj u Strateškom planu razvoja eZdravlja (SpeZ), ono podrazumijeva „stručne i poslovne zdravstvene postupke i procese podržane elektroničkim, informatičko-komunikacijskim uslugama: informatičke sustave u zdravstvenim ustanovama, uključujući razmjenu elektroničkim zdravstvenim zapisom (EZZ), distribuciju zdravstvenih informacija, privatnih $\mathrm{i}$ javnih, medicinska istraživanja i internetske servise za korisnike sustava zdravstva" (Ministarstvo zdravlja i HZZO, 2014:9).

U Strategiji su navedene koristi, vezane uz potporu razvoju sustava zdravstva, koje se od eZdravlja očekuju: veća dostupnost i kvaliteta zdravstvenih informacija zdravstve- 
nim djelatnicima i građanima, ušteda novaca i drugi resursi izbjegavanjem nepotrebnih, pogrešnih i redundantnih aktivnosti, pojednostavljenje korištenja zdravstvenih usluga, izravnija uloga korisnika sustava u brizi za svoje zdravlje, potpuni i kvalitetni podaci, pravovremeno na raspolaganju javnog zdravstva itd.

Slijedi nekoliko primjera nedostatne informacijske kulture i manjkavog upravljanja informacijama u projektima implementacije informacijsko-komunikacijske tehnologije (IKT) u zdravstvu uzrokovane izostankom sustavnog i strateškog upravljanja u eZdravlju.

a) Planiranje arhitekture eZdravlja u Hrvatskoj, podatkovna i procesna standardizacija i informatička certifikacija prepušteni su u ruke (velikim) isporučiteljima informatičkih programskih rješenja. Štoviše, često i inicijative za pojedine projekte dolaze od privatnih tvrtki koje razvijaju takva rješenja. Time sustav i njegove komponente postaju netransparentni i nepotrebno skupi za održavanje, komunikacija sa sustavima drugih isporučitelja komplicirana ili nemoguća, a svako zadovoljenje potrebe za proširenjem i unaprjeđenjem postaje višegodišnji proces. Etičke implikacije: problem institucionalne fragmentiranosti te ljudskih i financijskih kapaciteta javnih institucija uključenih u projekte eZdravlja, uza sve osjetljiviju poziciju privatnih isporučitelja u planiranju i provedbi sustava IKT.

b) Prema broju i financijskoj vrijednosti projekata eZdravlja, vodeću ulogu naručitelja i nositelja ima Hrvatski zavod za zdravstveno osiguranje. Tako je primjerice projekt eRecept postao najuspješnijim u Europi, jer je prioritetan iz perspektive osiguravatelja, ali su drugi strateški važniji projekti još uvijek daleko od pune implementacije (primjer eKartona). Etičke implikacije: mogućnost sekundarnog korištenja podataka s izvornim svrhom, oblikom i načinom prikupljanja primarno financijske prirode za potrebe procjene zdravstvenog stanja populacije i stvaranja javnih politika (engl. policy-making).

c) Nedosljednost u pokrivanju definiranih institucijskih javnih ovlasti te u uključivanju svih dionika u osmišljavanje novih procesa u zdravstvu zorno je vidljiv na nizu novih aplikativnih rješenja za tzv. Preventivne panele u primarnoj zdravstvenoj zaštiti. Iako idejno predstavljaju značajan napredak u podršci rada ordinacija primarne zdravstvene zaštite ne zadovoljavaju minimalne podatkovne standarde, javnozdravstvene preporuke i kliničke smjernice. Istovremeno, služe kao instrument financiranja zdravstvenih usluga, ali bez jasnih pokazatelja, bilo kvalitete podataka, bilo same kvalitete zdravstvene zaštite. Etičke implikacije: moralna i financijska upitnost planiranja i izvođenja projekta bez odgovarajuće prethodne komunikacije i usklađivanja relevantnih dionika, kao i posljedične evaluacije uspješnosti projekata.

d) Nemogućnost izgradnje novih zdravstvenih informacijskih sustava uz upotrebu postojeće infrastrukture zorna je na primjeru Centralnog zdravstvenog informacijskog sustava Republike Hrvatske (CEZIH), netransparentnosti njegove arhitekture (tzv. „blackbox"), nejasne procedure integracije i uporabe servisa, kao i nuždi da se za sve napredne informacije o navedenome konzultira vanjski izvršitelj. Etičke implikacije: pitanje opravdanosti funkcioniranja CEZIH-a gotovo isključivo na tehničkoj razi- 
ni, bez odgovarajućih strateških odrednica, točno definiranih uloga i ovlasti, sustavno planiranih ljudskih i financijskih resursa, pod jednim ili dva velika izvršitelja koji imaju prevelik utjecaj na same poslovne i razvojne odrednice.

e) U aktualnom odnosu Ministarstva, zdravstvenih zavoda i agencija nije sasvim jasno tko je odgovoran za provođenje vizije, misije i ciljeva strategije upravljanja podacima u hrvatskom zdravstvu, za kvalitetu provedbe strateških planova eZdravlja te koje su ingerencije svake pojedine zdravstvene ustanove. Hrvatski zavod za javno zdravstvo prema regulativi ima javnu ovlast planiranja, predlaganja i provedbe aktivnosti na uspostavi, razvoju i upravljanju zdravstvenim informacijskim sustavom. Međutim, u praksi su te ovlasti kroz posebne odluke, planove i provedbu u cijelosti izostale. Tako je izostao i najavljeni sporazum o interoperabilnosti u zdravstvu kojim se sustavi stavljaju u punu funkciju, formalizaciju te se osigurava održiva institucijska suradnja. Etičke implikacije: vrlo nepovoljna šarolikost prisutnih tehnologija, rješenja, načina ugovaranja i praksi implementacija rješenja IKT, sve bez nametnutih standarda, bilo komunikacijskih, arhitekturnih, ontoloških, bilo odabrane kombinacije.

f) Većina javnozdravstvenih registara $s$ dugom poviješću uporabe i uspostavljenim brojnim kontrolnim servisima s dionicima u zdravstvu te $s$ drugim sektorima javne uprave još uvijek nema jasno formalno-pravno uporište. Tako tek u digitalnoj eri postaje upitna legalnost metapodatkovnih standarda i uvriježenih procedura, kao i samog vođenja registara i pripadajućih kontrola temeljenih na izvornim podacima. Etičke implikacije: dovodi se u pitanje svrhovitost postojanja samih evidencija, pouzdanost proizvedenih informacija, kao i korištenje podataka za moralno ispravne svrhe što može uključivati i samu zaštitu privatnosti.

Vraćajući se na organizacijske dimenzije koje utječu na koheziju sustava, možemo zaključiti da je fragmentarna kultura eZdravlja posljedica poticanja raznolikosti unutar sustava, orijentiranja na ishod naspram procesa, fokusa na izvanjske elemente umjesto unutarnjih elementa te zanemarivanja sustavnog planiranja organizacijskih ljudskih resursa. Također, navedeni primjeri pokazuju kako informacijsku kulturu (Marchand i sur., 2001) eZdravlja najmanje određuju kontrola, informacijski integritet i transparentnost.

U Strateškom planu razvoja eZdravlja navedeno je kako „Uvođenje informacijsko-komunikacijskih tehnologija (IKT) u rad bilo pojedinca bilo organizacije znači promjenu načina rada pa sastavni dio svakog projekta informatizacije mora biti upravljanje promjenama (organizacija rada, izobrazba)" (Ministarstvo zdravlja i HZZO, 2014:28). Kako bi sustav eZdravlja značajno unaprijedio kvalitetu zdravstvene usluge, ali i uštedio znatna novčana sredstva te uspješno upravljao svojim postojećim sustavima i projektima, nužna je promjena njegove organizacijske i informacijske kulture. Polazišna točka promjene, a ujedno i preduvjet za ostvarivanje SPeZ-a, trebalo bi biti osnivanje središnjeg tijela (STeZ, „Središnje tijelo eZdravlja“) koje će dugoročno razvijati i nadzirati sustav eZdravlja. 


\section{ZAKLJUČAK}

Mnoštvo je primjera nedostatne kulture i nepouzdanosti zdravstvenih informacija na institucijskoj, upravljačkoj, profesionalnoj, medijskoj, pa čak i akademskoj razini. Popraćeni su brojnim izravnim i neizravnim etičkim implikacijama na zdravlje populacije i na prava pacijenata. Primjeri manjkavog upravljanja zdravstvenim informacijama, navedeni u ovom radu, ukazuju na gotovo potpuni izostanak strategije upravljanja podacima i informacijama u zdravstvu, što za posljedicu ima vrlo limitiranu povezanost dionika, nesustavni pristup rješavanju problema bez uzročne analize, ad-hoc planiranje i izvedbu rješenja, izostanak evaluacije, kao i otvaranje prostora za pojedinačne interese. Oni ujedno govore o ozbiljnosti prakse odlučivanja u hrvatskom zdravstvu, o populističkim kratkoročnim prioritetima, općenito institucionalnoj nezrelosti poslovanja i (ne)kulturi komunikacije.

Ozbiljan pristup strateškim odrednicama upravljanja zdravstvenim podacima i informacijama kritičan je korak ka sustavnom upravljanju eZdravljem. Kroz nove projekte jačanja institucijskih kapaciteta nasuprot inflaciji tehnički orijentiranih projekata, može se uspostaviti put ka učinkovitom upravljanju eZdravljem i općenito zdravstvenim sustavom. Primjer eZdravlja pokazuje, sukladno Marchand i sur. (2001), da interakcija ljudi, informacija i tehnologija ne može uspješno funkcionirati bez sposobnosti učinkovitog upravljanja infrastrukturom informacijske tehnologije, bez uspješnog upravljanja kvalitetom informacija te bez povezanosti i uspješne komunikacije, podjele ovlasti i uloga svih onih koji bi informacijama trebali upravljati. Potrebno je promicati ponašanja i vrijednosti koje potiču učinkovitu uporabu informacija, a u slučaju eZdravlja, to se posebno odnosi na povećanje razine informacijskog integriteta, transparentnosti i kontrole.

\section{LITERATURA}

Bergeron, P., Heaton, L., Choo, C. W., Detlor, B., Bouchard, D. i Paquette, S. (2007). Knowledge and information management practices in knowledge-intensive organizations: A case study of a Québec public organization. Proceedings of the Annual Conference of CAIS (Canadian Association for Information Science). URL: https:// journals.library.ualberta.ca/ojs.cais-acsi.ca/index.php/cais-asci/article/view/200 (29.01.2017.)

Choo, C. W., Bergeron, P., Detlor, B. i Heaton, L. (2008). Information culture and information use: An exploratory study of three organizations. Journal of the American Society for Information Science and Technology, 59(5): 792-804.

Choo, C. W. (2013). Information culture and organization aleffectiveness. International Journal of Information Management, 33: 775-779.

Curry, A. i Moore, C. (2003). Assessing information culture - an exploratory model. International Journal of Information Management, 23(2): 91-110.

Davies, H., Nutley, S. i Mannion, R. (2000). Organisational culture and quality of health care. Quality in Health Care, 9(2): 111-119. 
Marchand, D., Kettinger, W. i Rollins, J. (2001). Information orientation: The link to business performance. New York: Oxford University Press.

Ministarstvo zdravlja i Hrvatski zavod za zdravstveno osiguranje (HZZO) (2014). Strateški plan razvoja eZdravlja u Republici Hrvatskoj - SpeZ. URL: https://zdravlje. gov.hr/UserDocsImages/dokumenti/Programi,\%20projekti\%20i\%20strategije/ Strate\%C5\%A1ki-plan_razvoja_eZdravlja.pdf (29.01.2017.)

Scott, T., Mannion, R., Davies, H. i Marshall, M. (2003a). Implementing culture change in health care: theory and practice. International Journal for Quality in Health Care, 15(2): 111-118

Scott, T., Mannion, R., Davies, H. i Marshall, M. (2003b). The Quantitative Measurement of Organizational Culture in Health Care: A Review of the Available Instruments. Health Services Research, 38(3): 923-945. 


\title{
CULTURE OF HEALTH INFORMATION IN CROATIA
}

\author{
Ivan Pristaš, Damir Ivanković, Maja Valentić, Srđan Golubović, \\ Borna Pleše, Marko Brkić, Boris Barto and Tamara Poljičanin
}

\begin{abstract}
In this paper we focus on information culture as part of organizational culture, which controls data management and data use within the system. Health information is an important resource in planning, managing and evaluating the system of health, while health information management can have a direct effect on the functioning of the system of health, as well as the quality of health protection. We use the project of the implementation of information-communication technologies within the health system in Croatia in order to reveal the deficiencies in its information culture and data management. We found several reasons for these deficiencies: the absence of systematic and strategic management of eHealth, the existence of a non-transparent system, a high cost of its maintenance, institutional fragmentation, the lack of planned human and financial resources, defined roles and obligations, communication among the actors, as well as standards, procedures and evaluations. The authors suggest a serious approach to strategic goals of health data and information management as a critical step towards a more systematic and successful management of eHealth. In particular, we suggest the strengthening of institutional capacities, more successful communication, as well as better delegation of power and roles among the actors in charge of information management.
\end{abstract}

Key words: information culture, eHealth, data management, health system

\section{KULTUR DER GESUNDHEITSIFORMATIONEN IN KROATIEN}

\author{
Ivan Pristaš, Damir Ivanković, Maja Valentić, Srđan Golubović, \\ Borna Pleše, Marko Brkić, Boris Barto und Tamara Poljičanin
}

\section{Zusammenfassung}

In der Arbeit wird der Akzent auf die Informationskultur als ein Teil der Organisationskultur gesetzt, die das Datenmanagement bestimmt, sowie die Art und Weise, wie sie im System genutzt wird. Die Gesundheitsiformationen stellen eine außerordentlich wichtige Ressource bei der Planung, Führung und Bewertung des Gesundheitssystems dar, während das Datenmanagement im Gesundheitswesen das Funktionieren des Gesundheitssystems sowie die Qualität des Gesundheitsschutzes unmittelbar beeinflußt. In der Arbeit werden einige Beispiele mangelhafter Informationskultur und mangelhaften Datenmanagements in den Projekten der Implementierung von Informations- und Kommunikationstechnologien im Gesundheitswesen der Republik Kroatien angeführt. Die Ursache sieht man im Fehlen eines systematischen und strategischen Managements in der e-Gesundheit und die angeführten Beispiele weisen auf das Problem der Nichttransparenz des Systems und dessen zu teurer Wartung hin, auf den institutionellen Fragmentarismus, auf das Fehlen von systematisch geplanten menschlichen und finanziellen Ressourcen, auf das Ausbleiben von definierten Rollen und Befugnissen, auf das Fehlen der Kommunikation unter den Teilnehmern, sowie auf das Nichtbestehen von Standards, Prozeduren und Evaluationen. Die Autoren schlagen seriöse Ansätze der strategischen Determinanten im Management von Gesundheitsdaten und Informationen vor, einen kritischen Schritt in Richtung eines systematischen und erfolgreichen Managements der e-Gesundheit. Als mögliche Aktivitäten werden die Stärkung von institutionellen Kapazitäten, eine erfolgreichere Kommunikation, sowie die Teilung von Befugnissen und Rollen der Teilnehmer vorgeschlagen.

Schlüsselwörter: Informationskultur, e-Gesundheit, Datenmanagement, Gesundheitssystem 